\title{
DESENVOLVIMENTO DE TECNOLOGIA DE FABRICAÇÃO DE REQUEIJÃO CREMOSO COM TEOR REDUZIDO DE GORDURA
}

\author{
Development of technology for production of reduced fat \\ processed cheese
}

\author{
Adriana Torres Silva e Alves ${ }^{*}$, Leila Maria Spadoti ${ }^{1}$, Patrícia Blumer Zacarchenco ${ }^{I}$, \\ Ariene Gimenes Fernandes Van Dender
}

\begin{abstract}
RESUMO
Observa-se uma participação cada vez maior na dieta da população brasileira de alimentos com teor de gordura reduzido, tendência esta também verificada em muitos outros países. Neste contexto, o objetivo foi estudar os parâmetros de fabricação e desenvolver um processo de fabricação de requeijão cremoso com teor de gordura reduzido. Na primeira etapa deste estudo, modificações foram realizadas na tecnologia tradicional de fabricação do requeijão cremoso para a obtenção de um produto com teor de gordura reduzido. Na segunda etapa estudou-se a fabricação de requeijão cremoso com teor de gordura reduzido produzido com e sem adição de concentrado protéico de soro (CPS 34\%) e utilizando-se dois tipos de sais emulsificantes, JOHA S9 e JOHA PZ, resultando em quatro diferentes formulações. Os cálculos foram feitos para que o produto final tivesse $10 \%$ de gordura e $33 \%$ de extrato seco total. $\mathrm{O}$ produto que apresentou os melhores resultados foi aquele produzido com massa obtida por acidificação direta a quente $\left(68{ }^{\circ} \mathrm{C}\right.$ a $\left.70{ }^{\circ} \mathrm{C}\right)$, utilizando-se $1,3 \%$ de sal JOHA S9 na fusão da massa e 2\% de CPS 34\% na substituição parcial da gordura, ambos calculados em relação à massa básica. Além disso, a adição do CPS 34\% ao produto, quando o mesmo se encontrava a uma temperatura de aproximadamente $70{ }^{\circ} \mathrm{C}$, foi fundamental para obtenção de um produto com textura adequada.
\end{abstract}

Palavras-chave: queijo processado; substituto de gordura; proteína láctea.

1 Instituto de Tecnologia de Alimentos (ITAL), Avenida Brasil, 2880, Caixa Postal 139, 13070-178, Campinas, SP, Brasil. E-mail: atorres@ital.sp.gov.br

* Autor para correspondência.

Recebido / Received: 04/11/2014

Aprovado / Approved: 06/04/2015 


\begin{abstract}
An increasing share of foods with reduced fat has been observed in the diet of the Brazilian population, a trend also seen in many other countries. In this context, our-aim was to study the manufacturing parameters and to develop a process to produce a spreadable processed cheese (requeijão cremoso) with reduced fat content. In the first stage of this study, modifications were performed in the traditional manufacturing process of requeijão cremoso with regular fat content to produce a reduced fat product. During the second stage of this study, two reduced fat cheeses, with and without the addition of whey protein concentrate (WPC) were developed, both using JOHA S9 and JOHA PZ as emulsifying salts, resulting in four different formulations. The amounts of cream and water used in both products were calculated in order to obtain a final product with $10 \%$ fat and $33 \%$ total solids. The product which presented the best results was produced with curd obtained by direct acidification of skimmed milk heated at $68-70{ }^{\circ} \mathrm{C}$, using $1,3 \%$ emulsifying salt JOHA S9 in the melting process and $2 \%$ WPC $34 \%$ as a partial fat substitute, both calculated as a percentage of the amount of curd used as raw material. It was also important to add WPC $34 \%$ to the product at the first cooking step of the process $\left(70^{\circ} \mathrm{C}\right)$, in order to obtain a final product with the typical spreadable texture of the traditional requeijão cremoso.
\end{abstract}

Keywords: processed cheese; fat substitute; dairy protein.

\section{INTRODUÇ̃̃̃O}

Os documentos do Ministério da Saúde "Política Nacional de Alimentação e Nutrição - PNAN" (BRASIL, 2012) e "Guia Alimentar para a População Brasileira” (BRASIL, 2005), na Diretriz 5 "Leite e derivados, carnes e ovos", recomendam o consumo diário de três porções de leite e derivados que devem conter, preferencialmente, menores teores de gordura para adultos. Outros documentos do governo brasileiro (BRASIL, 2011) mostram a preocupação com o crescimento da incidência de Doenças Crônicas não Transmissíveis (DCNT) no país, entre elas a obesidade e as doenças coronarianas. Muitas destas doenças podem ser atenuadas ou prevenidas com mudanças no estilo de vida e na alimentação, sendo uma destas mudanças a ingestão de menores teores de gordura.

O consumo de altas quantidades de gordura está relacionado com o aumento do risco da obesidade e ao desenvolvimento de alguns tipos de câncer (NACHAY, 2008), sendo que a ingestão de ácidos graxos saturados está associada ao aumento do colesterol sanguíneo e às doenças coronarianas. As doenças cardiovasculares, segundo a Organização Mundial da Saúde (OMS, 2009), representam a principal causa de mortalidade no Brasil e no mundo, sendo também importante causa de incapacidade física. Em 2004, cerca de $29 \%$ do total de mortes ocorridas no mundo (17,1 milhões) foram causadas por doenças cardiovasculares e estima-se que, em 2030, elas sejam a causa da morte de 23,6 milhões de pessoas (OMS, 2009).

Queijos processados são produtos lácteos fabricados por aquecimento de uma mistura ou de um único tipo de queijo por meio do uso de sais emulsificantes (WEISEROVÁ et al., 2011). O requeijão cremoso é um queijo processado tipicamente brasileiro, de grande valor comercial, elaborado a partir do tratamento mecânico, químico e térmico da massa proteica obtida pela precipitação ácida ou pela coagulação enzimática de leite, adicionada de creme de leite, sal, água e sais 
fundentes (FERNANDES; MARTINS, 1980). Os queijos fundidos, caso do requeijão cremoso, estão entre os que contêm altos teores de gordura e colesterol. Contudo, é tecnologicamente possível o desenvolvimento de formulações de queijos e, em especial, de requeijão com teor reduzido de gordura.

Um aspecto importante a ser destacado no caso da elaboração de produtos com teor reduzido de gordura é que, ao mesmo tempo em que o interesse por produtos lácteos com baixo teor de gordura tem aumentado, os consumidores também esperam que esses produtos mantenham a textura e as características funcionais similares às dos tradicionais (MISTRY, 2002). No entanto, apesar de muitos anos de pesquisa, este aspecto parece ainda não ter sido resolvido satisfatoriamente.

O creme de leite, responsável pelas principais características sensoriais do requeijão cremoso, é também responsável pelo seu alto teor de gordura e deve ser substituído parcialmente no requeijão light por outro ingrediente que garanta a obtenção das características originais em um produto com menor teor de gordura (SAMPAIO; BRANDÃO, 1995). Uma opção consiste em realizar algumas modificações na tecnologia de fabricação e, conjuntamente, utilizar um substituto de gordura.

O concentrado proteico de soro (CPS) é um ingrediente que vem sendo bastante utilizado na substituição parcial da gordura em produtos lácteos. Esta substância é capaz de imitar as propriedades sensoriais e físicas dos triacilgliceróis (ROLLER; JONES, 1996), simular a textura e a sensação de gordura na boca, estabilizar emulsões e dar corpo ao produto (SOLER, 2014).

O concentrado proteico de soro é obtido a partir da concentração das proteínas presentes no soro (ou soroproteínas) por meio de membranas de ultrafiltração (USDEC, 2004). As soroproteínas possuem elevado valor nutricional e propriedades funcionais interessantes para aplicação na melhoria da qualidade dos alimentos (ANTUNES, 2003; USDEC, 2004). Por fim, o estudo de mais uma possibilidade de aplicação de CPS em alimentos também é importante considerando-se a atual preocupação mundial com a questão de sustentabilidade do meio ambiente, uma vez que o soro é um subproduto da indústria laticinista que possui elevado poder poluente e cujo tratamento para descarte é oneroso.

Tendo em vista os aspectos citados anteriormente, este trabalho teve como objetivos estudar os parâmetros de fabricação e desenvolver uma tecnologia para produção de requeijão com teor de gordura reduzido, testando a utilização ou não de concentrado protéico de soro (CPS 34\%) para substituição parcial da gordura, bem como dois tipos de sais fundentes (JOHA S9 e JOHA PZ).

\section{MATERIAL E MÉTODOS}

\section{Fabricação do requeijão cremoso}

O estudo da fabricação do requeijão com teor reduzido de gordura envolveu duas etapas: realização de experimentos preliminares para definição de alguns parâmetros referentes à tecnologia básica de fabricação de requeijão cremoso, e uma segunda etapa constando de elaboração de requeijões onde se estudou o efeito da adição ou não de um substituto de gordura (CPS 34\%) e do uso de dois diferentes tipos de sais fundentes (JOHA S9 e JOHA PZ).

Nos experimentos preliminares, procurou-se estudar modificações em alguns parâmetros da tecnologia de fabricação do requeijão cremoso, visando à obtenção de um produto com baixo teor de gordura que apresentasse boas características sensoriais e de textura. Para obtenção deste requeijão trabalhou-se com leite desnatado e não com leite integral e tal procedimento exigiu que vários parâmetros relacionados à obtenção 


\section{Leite desnatado}

ת

Coagulação ácida a quente (temperaturas testadas $=80-82{ }^{\circ} \mathrm{C}$ e $68-70{ }^{\circ} \mathrm{C}$ ) com adição de ácido láctico $85 \%$ diluído (porcentagens de ácido testadas $=\mathbf{0 , 2 8} \% \mathrm{e}$

$0,30 \%$ em relação ao leite $(\mathrm{v} / \mathrm{v}))($ diluições testadas $=1: 4$ e 1:10, ácido:água)

ת

Repouso da massa por 10 minutos

ת

Dessoragem

ת

Enformagem da massa básica

ת

Prensagem (dobro do peso da massa básica, em prensa mecânica por 15 minutos de cada lado)

ת

Pesagem e moagem da massa básica

ת

Homogeneização da mistura: massa básica + cloreto de sódio $(1,5 \%$ em relação à massa básica $(\mathrm{m} / \mathrm{m})$ ) + sal fundente JOHA S9 (porcentagens testadas de sal fundente $=\mathbf{2 , 5 \%}$, $1,5 \%$ e $1,3 \%$ em relação à massa básica $(\mathrm{m} / \mathrm{m}))$

ת

Mistura do creme de leite e metade da água a ser utilizada

ת

\section{$\mathbf{1}^{\circ}$ Cozimento:}

Adição do CPS 34\% e do restante da água

(porcentagens de CPS 34\% testadas $=3 \%$ e $2 \%$ em relação ao produto final $(\mathrm{m} / \mathrm{m}$ ) e $3 \%$ e $2 \%$ em relação à massa básica $(\mathrm{m} / \mathrm{m}))$

(fases de adição do CPS 34\% testadas = início da fusão ou após o produto ter atingido a temperatura de cerca de $70^{\circ} \mathrm{C}$ )

Manutenção da mistura a $70{ }^{\circ} \mathrm{C} / 5$ minutos, sob vácuo e agitação

ת

\section{$2^{\circ}$ Cozimento:}

Aquecimento a $87^{\circ} \mathrm{C} / 3$ minutos sob vácuo e agitação intensa

$\sqrt{2}$

Envase a quente, resfriamento e estocagem em câmara fria $\left(4 \pm 2{ }^{\circ} \mathrm{C}\right)$

Figura 1 - Representação esquemática da tecnologia de fabricação de requeijão cremoso com teor reduzido de gordura, adotada nos testes preliminares 
da massa e do requeijão propriamente dito fossem estudados.

Nos experimentos preliminares adotou-se a tecnologia de fabricação esquematizada na Figura 1 e detalhada abaixo, sendo que nestes experimentos os parâmetros avaliados foram: a) a temperatura de precipitação do leite desnatado para obtenção da massa $\left(80{ }^{\circ} \mathrm{C}-82^{\circ} \mathrm{C}\right.$ e $\left.68{ }^{\circ} \mathrm{C}-70^{\circ} \mathrm{C}\right)$; b) a quantidade de ácido láctico usada na precipitação $(0,28 \%$ e $0,30 \%$ de ácido em relação ao leite $(\mathrm{v} / \mathrm{v}))$; c) a diluição do ácido láctico em água filtrada (1:10 e 1:4); d) a quantidade de sal fundente JOHA S9 $(2,5 \%, 1,5 \%$ e $1,3 \%$ em relação à massa básica $(\mathrm{m} / \mathrm{m}))$; e) a quantidade de concentrado protéico de soro $(3 \%$ e $2 \%$ em relação ao produto final $(\mathrm{m} / \mathrm{m})$ e $3 \%$ e $2 \%$ em relação à massa básica $(\mathrm{m} / \mathrm{m}))$; f) o momento de adição do concentrado (início da fusão ou após o produto ter atingido a temperatura de cerca de $70{ }^{\circ} \mathrm{C}$ ).

No processo de obtenção da massa básica não foi realizada a lavagem da mesma, visando um $\mathrm{pH}$ mais baixo. A massa obtida foi submetida às análises físicas e químicas necessárias $(\mathrm{pH}$, extrato seco total (EST) e teor de gordura) para realização dos cálculos das quantidades de água e gordura a serem adicionadas, para obtenção de um produto contendo aproximadamente $30 \%$ de gordura no extrato seco e $33 \%$ de extrato seco total. Tais cálculos foram realizados de acordo com Fernandes (1981).

Os requeijões foram elaborados em uma máquina trituradora-homogeneizadora Stephan UMM-SK 40E. Os ingredientes sólidos (sal (cloreto de sódio) e sal fundente) foram adicionados à massa, triturando-se a mistura por um minuto, sem aquecimento. A seguir, foram adicionados o creme e a metade da água a ser utilizada. Posteriormente iniciou-se o processo de fusão da massa, com aquecimento por injeção direta de vapor, sendo que, durante a etapa de primeiro cozimento, testou-se o efeito da adição de diferentes concentrações de CPS na mistura, bem como qual o momento mais adequado para esta adição.

Este primeiro cozimento foi realizado a $70{ }^{\circ} \mathrm{C}$ sendo mantida esta temperatura por cinco minutos (velocidade baixa). $\mathrm{O}$ concentrado proteico de soro adicionado à mistura foi previamente dissolvido em água.

$\mathrm{O}$ segundo aquecimento foi realizado com agitação (velocidade alta) até $87^{\circ} \mathrm{C}$ a $90^{\circ} \mathrm{C}$. $\mathrm{O}$ produto foi mantido nesta temperatura por três minutos e, em seguida, foi embalado a quente em copos de vidro de 250 gramas, com tampas metálicas munidas de sistema de fechamento do tipo "abre-fácil", resfriado em água à temperatura ambiente e armazenado em câmara fria na temperatura de $4^{\circ} \mathrm{C} \pm 2{ }^{\circ} \mathrm{C}$. Com relação ao sistema de embalagem utilizado, as tampas são produzidas em folha de flandres e possuem um septo a base de plastissol vedando uma perfuração no centro da tampa. Com a remoção do septo ocorre a perda de vácuo no interior da embalagem e, portanto, a fácil retirada da tampa.

$\mathrm{Na}$ segunda etapa desta pesquisa foram realizados dois processamentos, sendo que em cada um deles foram produzidas quatro formulações de requeijão cremoso com teor reduzido de gordura.

Nesta segunda etapa do estudo, para obtenção dos requeijões cremosos com teor de gordura reduzido, adotou-se a mesma tecnologia apresentada na Figura 1. Porém, baseando-se nos resultados obtidos nos experimentos preliminares, foram selecionados os seguintes procedimentos: a precipitação do leite foi feita pela adição de $0,3 \%$ de ácido láctico grau alimentar (diluído na proporção de 1:4, ácido:água) ao leite, na temperatura de aproximadamente $68-70{ }^{\circ} \mathrm{C}$. A massa obtida após dessoragem, enformagem, prensagem, moagem e pesagem foi submetida ao processo de fusão, no qual se adotou o uso de 1,3\% de sal fundente em relação à massa.

As variações estudadas nessa segunda etapa foram a adição ou não do CPS $34 \%$ e o tipo de sal fundente utilizado, resultando em 
quatro formulações (Figura 2). O concentrado proteico de soro $34 \%$, quando utilizado na formulação, foi adicionado na quantidade de $2 \%$ em relação à massa básica. O CPS foi adicionado após a mistura (massa, sal, sal fundente, água e creme) ter atingido a temperatura de cerca de $70{ }^{\circ} \mathrm{C}$.

Conforme esquematizado na Figura 2, em duas formulações (Formulação 1 e Formulação 2) utilizou-se o sal JOHA S9 (mistura de fosfatos de sódio) e em outras duas (Formulação 3 e Formulação 4) o sal JOHA PZ (mistura de citrato de sódio, polifosfato de sódio e ortofosfato de potássio), que é recomendado para melhorar a fusão em queijos processados com baixo teor de gordura. Para ambos os sais, a proporção utilizada foi de $1,3 \%$ calculada em relação à massa básica.

\section{Determinações analíticas}

Foram feitas análises físicas, químicas e sensoriais dos produtos (Formulações 1, 2, 3 e 4) após 2 dias de estocagem. O leite utilizado foi avaliado quanto aos teores de gordura (INSTITUTO ADOLFO LUTZ, 2005) e de extrato seco total (IDF, 1982).

Nas massas e nos requeijões foram realizadas as seguintes análises: determinação do $\mathrm{pH}$ e dos teores de extrato seco total e de gordura. $\mathrm{O} \mathrm{pH}$ foi determinado em um potenciômetro Micronal B-375. O EST foi

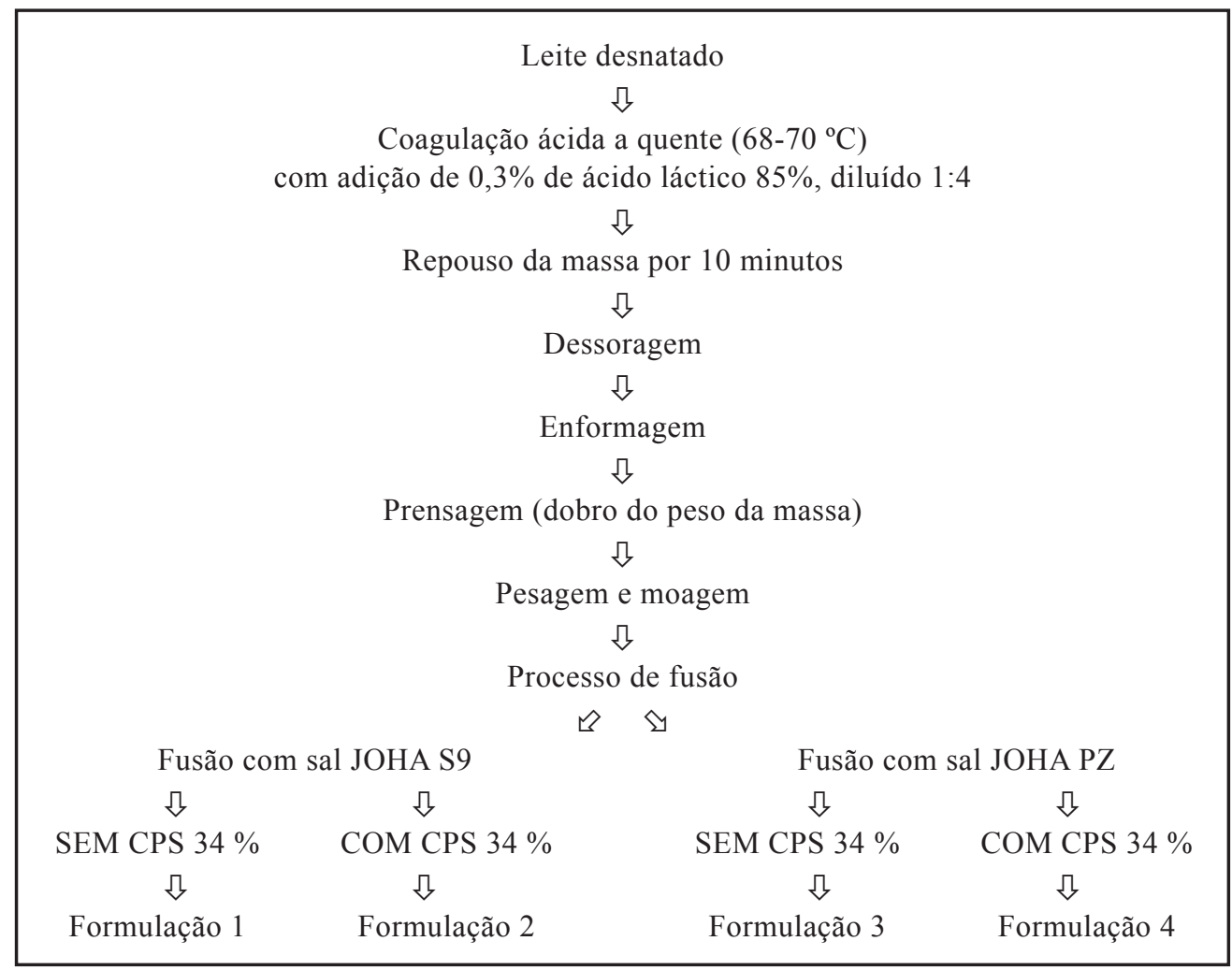

Figura 2 - Representação esquemática das etapas de fabricação de requeijão cremoso com teor reduzido de gordura realizadas na segunda etapa do estudo 
determinado de acordo com IDF (1982) e o teor de gordura por meio de uma adaptação do método de Mojonnier (SILVA et al., 2002) feita para o requeijão cremoso com baixo teor de gordura a partir da metodologia oficial preconizada pela AOAC (1997). As alterações na metodologia oficial foram feitas baseando-se em técnica descrita por Atherton; Newlander (1981), consistindo a adaptação da realização de digestão ácida a quente, além da alcalina.

Para avaliação dos resultados dos requeijões obtidos foi determinada a ANOVA e para a comparação entre médias dos tratamentos utilizou-se o teste de Tukey, estabelecendo-se $\mathrm{p}<0,05$ como nível de significância.

Para avaliar as características de aparência, formação de fio, brilho, aroma, textura/sensação na boca e sabor do produto foi conduzida, 2 a 3 dias após a fabricação dos requeijões, uma avaliação sensorial consensual por equipe de seis julgadores selecionados quanto à acuidade sensorial, com descrição das características detectadas (ISO, 2005). Na avaliação, a equipe de julgadores empregou uma escala de 0 a 10 para quantificar as intensidades das características que poderiam variar de um tratamento para outro. Nesta escala, o valor 0 corresponde a inexistente ou intensidade fraca, o valor 5 , à intensidade moderada e o valor 10 à intensidade extremamente forte.

\section{RESULTADOS E DISCUSSÃO}

\section{Resultados da etapa de experimentos preliminares}

Nos experimentos preliminares observou-se que a melhor condição para obtenção da massa básica com características adequadas para o processo de fusão consistiu em precipitar o leite desnatado a uma temperatura mais baixa $\left(68-70{ }^{\circ} \mathrm{C}\right)$ do que aquela normalmente utilizada para leite integral
(80-82 $\left.{ }^{\circ} \mathrm{C}\right)$. Observou-se que, quando a precipitação do leite desnatado foi feita a $82{ }^{\circ} \mathrm{C}$, a massa apresentou-se muito seca e dura, não fundindo bem, resultando num produto final arenoso.

Modificações na tecnologia de fabricação são a forma mais simples e econômica de se melhorar o sabor e a textura dos queijos com teor de gordura reduzido. Uma dessas modificações se baseia no aumento da retenção de umidade na coalhada, o que pode ser obtido, por exemplo, por meio do uso de temperaturas mais baixas no cozimento da massa. Aumentando-se o conteúdo de umidade pode-se obter, além da textura típica, um pouco da lubrificação ou sensação de cremosidade na boca e da maciez proporcionadas pela gordura. Queijos com redução na concentração de gordura apresentam também menor rendimento, porque a gordura constitui normalmente $50 \%$ ou mais do extrato seco total. Aumentando-se a umidade aumenta-se também o rendimento nesses queijos (DRAKE; SWANSON, 1995).

Nos experimentos realizados constatou-se que com relação ao uso de ácido láctico, a melhor condição testada foi aquela em que a precipitação do leite foi feita com o uso de $0,3 \%$ de ácido láctico, diluído na proporção de 1:4 (ácido: água). Esta condição resultou em pequeno aumento no rendimento (cerca de $2 \%$ ) e em maior acidificação da massa obtida, tornando-a mais úmida e macia, facilitando sua fusão. O’Mahony et al. (2006) e Brickley et al. (2008) relatam que o conteúdo de umidade de massas básicas aumenta com a diminuição dos valores de $\mathrm{pH}$ e do conteúdo total de cálcio no sistema.

Essa maior acidificação da massa básica também contribuiu positivamente para melhoria do sabor, já que os queijos com baixo teor de gordura são mais insípidos, e da textura do produto final. Por sua vez, com o uso de $0,28 \%$ de ácido láctico diluído na proporção $1: 10$, a massa obtida apresentou 
consistência pegajosa (similar a de uma cola) e textura dura, o que dificultava seu corte/ manipulação.

Com relação às porcentagens de sais fundentes testadas, o uso de $1,3 \%$ de sal foi adequado para a fusão da massa obtida nas condições definidas anteriormente. Procurou-se definir a menor quantidade de sais fundentes necessária para uma fusão satisfatória e textura desejada, evitando alteração de sabor. Os sais fundentes não perdem seu sabor próprio quando formam complexos com os componentes do queijo (PATART, 1984; NEVES; DUCRUET, 1988; BRICKLEY et al., 2008) e, em produtos com baixo teor de gordura, o sabor residual pode ser mais pronunciado (YACKEL; COX, 1992).

Nos experimentos preliminares foram testadas as porcentagens de $2 \%$ e $3 \%$ de CPS $34 \%$ calculadas em relação à massa básica, e de $2 \%$ e $3 \%$ calculadas em relação ao produto final. A porcentagem de $2 \%$ calculada em relação à massa básica apresentou resultados satisfatórios quando comparada às demais, sendo escolhida por ser a mais econômica. Avaliou-se ainda qual o procedimento mais adequado para adição do concentrado de soro no processo. Com relação ao momento para adição do CPS, observou-se que quando o mesmo foi adicionado no início da fabricação do requeijão, o produto final apresentouse arenoso e com grumos. Por outro lado, quando a adição foi realizada após o primeiro cozimento (ao redor de $70{ }^{\circ} \mathrm{C}$ ), o produto obtido apresentou textura lisa. Além disso, a adição do CPS diluído em parte da água calculada para a formulação facilitou a incorporação do CPS ao produto.

\section{Resultados da etapa de elaboração de re- queijões onde se estudou o efeito da adição ou não de CPS 34\% e do uso dos sais fun- dentes JOHA S9 e JOHA PZ}

Os teores médios $(\mathrm{n}=2$ experimentos $)$ de extrato seco total e de gordura dos leites utilizados nos processamentos, da segunda etapa deste projeto, foram, respectivamente, de $9,10 \%$ e $0,1 \%$.

A Tabela 1 mostra os valores médios $(\mathrm{n}=2$ experimentos) das características da massa básica usada na fabricação dos requeijões, da segunda etapa do projeto.

$\mathrm{Na}$ Tabela 2 são apresentadas a quantidade e porcentagem (em relação à massa) de cada ingrediente utilizado nas formulações estudadas.

Tabela 1 - Valores médios ( $\mathrm{n}=2$ experimentos) das análises realizadas na massa usada na fabricação dos requeijões elaborados na segunda etapa do projeto

\begin{tabular}{cc}
\hline Análises & Resultados \\
\hline $\mathrm{pH}$ & 5,63 \\
EST $(\%)$ & 47,43 \\
Gordura $(\%)$ & 0,5 \\
\hline
\end{tabular}

Analisando-se os dados da Tabela 3 verifica-se que não houve variação significativa $(p>0,05)$ entre os tratamentos com relação ao $\mathrm{pH}$, sendo que os valores obtidos para os requeijões situaram-se dentro dos limites estabelecidos na legislação, ou seja, entre 5,7 e 5,9 (BRASIL, 1997). O pH dos requeijões com baixo teor de gordura, fabricados com massa obtida por meio de precipitação ácida a quente do leite foi menor do que aqueles fabricados com teor de gordura normal encontrados na literatura. Este $\mathrm{pH}$ mais baixo foi considerado positivo para este tipo de produto. Os produtos com baixo teor de gordura apresentam-se insípidos e a acidez um pouco mais alta melhorou o sabor do produto.

A maioria das bactérias apresenta crescimento ótimo em um valor de $\mathrm{pH}$ neutro, sendo que seu crescimento decresce com o abaixamento do pH do meio (FOX et al., 2000). $\mathrm{O}$ pH mais baixo previne ainda a formação de 
esporos microbianos e a produção de toxinas (KAPOOR; METZGER, 2009). Assim, menores valores de $\mathrm{pH}$ contribuem para melhoria da estabilidade microbiológica deste produto, que possui teor de umidade alto.

Os teores de gordura e de extrato seco situaram-se dentro dos valores esperados para obtenção de um requeijão com teor reduzido de gordura. Em todas as formulações, a porcentagem de redução em gorduras totais foi de aproximadamente 50-60\%, considerando-se que o produto tradicional apresenta aproximadamente $20-24 \%$ de gordura. Esta redução está de acordo com a RDC n 54/2012
(ANVISA, 2012), a qual estabelece que para um produto ser considerado "reduzido" em gorduras, deve ter uma redução mínima de $25 \%$ em gorduras totais comparando-se com o produto tradicional.

O produto da Formulação 1, ao qual não se adicionou o CPS, apresentou a textura um pouco mais mole e menor intensidade de brilho, sendo que para esta formulação ocorreu uma pequena separação de água na superfície, fato não observado na Formulação 2, na qual se utilizou o CPS. Esta separação de água na superfície também foi observada na Formulação 3, mas não na Formulação 4,

Tabela 2 - Quantidade de cada ingrediente empregado nas formulações

\begin{tabular}{lcccc}
\hline \multicolumn{1}{c}{$\begin{array}{c}\text { Formulações } \\
\text { Ingredientes }\end{array}$} & $\begin{array}{c}\text { Formulação 1* } \\
\text { Peso }(\mathrm{kg})\end{array}$ & $\begin{array}{c}\text { Formulação 2 } \\
\text { Peso }(\mathrm{kg})\end{array}$ & $\begin{array}{c}\text { Formulação 3 } \\
\text { Peso (kg) }\end{array}$ & $\begin{array}{c}\text { Formulação 4 } \\
\text { Peso (kg) }\end{array}$ \\
\hline Massa & 4,87 & 4,87 & 4,87 & 4,87 \\
Sal fundente $(1,3 \%)$ & 0,063 & 0,063 & 0,063 & 0,063 \\
$\mathrm{NaCl} \mathrm{(2 \% )}$ & 0,098 & 0,098 & 0,098 & 0,098 \\
CPS (2\%) & - & 0,098 & - & 0,098 \\
Creme (c/40\% de gordura) & 2,76 & 2,76 & 2,76 & 2,76 \\
Água & 1,94 & 1,94 & 1,94 & 1,94 \\
\hline
\end{tabular}

*Formulação 1: requeijão elaborado com sal fundente S9 e sem CPS; Formulação 2: requeijão elaborado com sal fundente S9 e com CPS; Formulação 3: requeijão elaborado com sal fundente PZ e sem CPS e Formulação 4: requeijão elaborado com sal fundente $\mathrm{PZ}$ e com CPS.

Tabela 3 - Valores médios ( $\mathrm{n}=2$ experimentos) das características físico-químicas dos requeijões com teor reduzido de gordura

\begin{tabular}{ccccc}
\hline $\begin{array}{c}\text { Amostras } \\
\text { Análises }\end{array}$ & Formulação $1^{*}$ & Formulação 2 & Formulação 3 & Formulação 4 \\
\hline pH & $5,75^{\mathrm{a}} \pm 0,03$ & $5,74^{\mathrm{a}} \pm 0,04$ & $5,68^{\mathrm{a}} \pm 0,05$ & $5,69^{\mathrm{a}} \pm 0,04$ \\
EST (\%) & $29,97^{\mathrm{b}} \pm 0,37$ & $31,71^{\mathrm{a}} \pm 0,24$ & $30,75^{\mathrm{ab}} \pm 0,36$ & $30,76^{\mathrm{ab}} \pm 0,15$ \\
Gordura $(\%)$ & $10,23^{\mathrm{b}} \pm 0,33$ & $10,44^{\mathrm{b}} \pm 0,35$ & $11,19^{\mathrm{a}} \pm 0,41$ & $11,13^{\mathrm{a}} \pm 0,42$ \\
GES** $(\%)$ & $34,13^{\mathrm{ab}} \pm 1,50$ & $32,92^{\mathrm{b}} \pm 1,43$ & $36,39^{\mathrm{a}} \pm 1,48$ & $36,18^{\mathrm{a}} \pm 1,64$ \\
\hline
\end{tabular}

As amostras (média \pm desvio padrão) seguidas de letras iguais na mesma linha não diferem ao nível de $5 \%$.

*Formulação 1: requeijão elaborado com sal fundente S9 e sem CPS; Formulação 2: requeijão elaborado com sal fundente S9 e com CPS; Formulação 3: requeijão elaborado com sal fundente PZ e sem CPS e Formulação 4: requeijão elaborado com sal fundente $\mathrm{PZ}$ e com $\mathrm{CPS}$.

$* * \mathrm{GES}=(\%$ gordura $/ \%$ EST $) \times 100$. 
embora ambas não tenham diferido estatisticamente em termos de porcentagem de extrato seco total.

Assim sendo, pode-se atribuir a ausência de separação de água nas formulações 2 e 4 ao uso do CPS. As proteínas do soro possuem uma conformação globular sendo que o aumento da temperatura e o $\mathrm{pH}$ levam ao desdobramento parcial das moléculas dos concentrados protéicos de soro (CPS), deixando-as livres para associarem-se ou agregarem-se a outras moléculas (LUCCA; TEPPER, 1994).

$\mathrm{O} \mathrm{pH}$, a concentração de proteína e a temperatura exercem um papel importante no tipo de estrutura que será formada durante a reação. $\mathrm{O}$ efeito do $\mathrm{pH}$ nas propriedades reológicas dos queijos processados contendo CPS ocorre principalmente devido à interação das soroproteínas, particularmente a $\beta$-lactoglobulina, com as caseínas formando uma forte estrutura de rede, resultando num queijo processado firme e estável mesmo com baixas concentrações de proteína e altos níveis de umidade (LEE; ANEMA, 2009). Temperaturas moderadas $\left(60-90{ }^{\circ} \mathrm{C}\right)$ e baixos níveis de proteína $(<10 \%)$, caso dos requeijões, favorecem a formação de moléculas pequenas que se ligam à água e aumentam a viscosidade de alimentos, dando corpo e melhorando a textura. Essa propriedade de retenção de água ajuda a controlar a sinérese do produto (USDEC, 2004).

Nos tratamentos onde se utilizou o sal fundente JOHA PZ, a base de citrato, (Formulação 3 e Formulação 4), os requeijões apresentaram uma boa fusão e brilho e pequena formação de fios, porém, tiveram um leve sabor de citrato (azedo), não característico do requeijão cremoso tradicional, o que acabou levando a uma rejeição dos produtos por parte dos julgadores (Tabela 4). Os citratos são sais bem solúveis e que possuem bom poder de dissolução da proteína, mas os queijos processados com os mesmos mostram pequena tendência de absorver água e suas estruturas tendem a se manter firme e pesada. Tais sais também apresentam como desvantagem a falta de ação cremificante e podem conferir sabores indesejáveis aos queijos (salgado, amargo, azedo) (MAURER-ROTHMANN, 2005; VAN DENDER et al., 2014).

Assim, as formulações obtidas com o sal JOHA S9 (Formulação 1 e Formulação 2) foram consideradas mais adequadas para o requeijão, pela rejeição provocada pelo sabor de citrato nas formulações 3 e 4 .

A Figura 3 mostra o produto obtido empregando-se a Formulação 2 (com CPS), que foi considerada a melhor formulação, em termos sensoriais, pelos avaliadores.
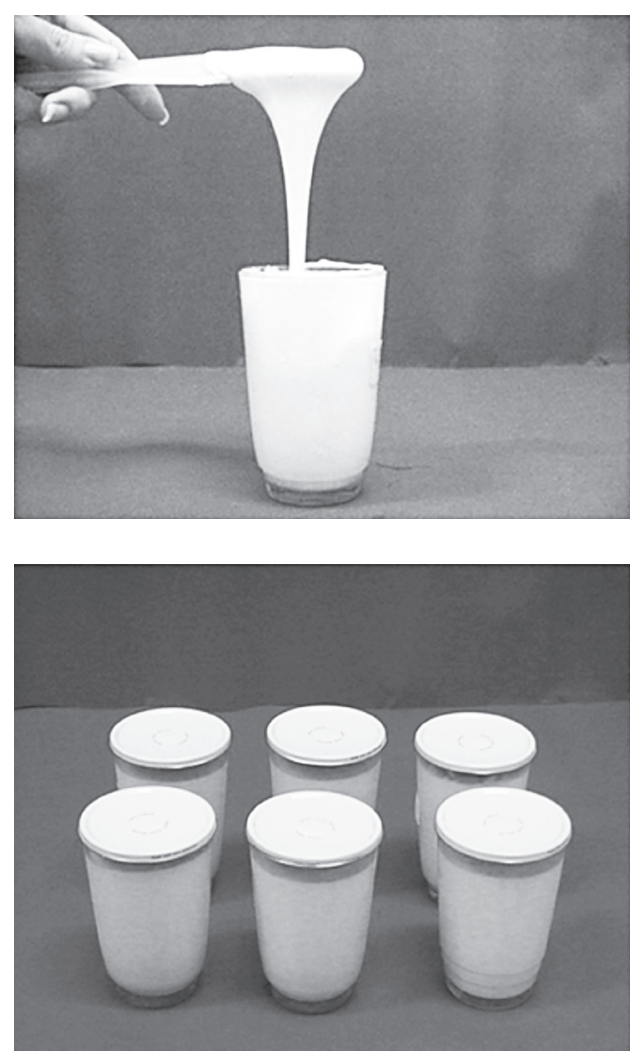

Figura 3 - Fotos ilustrativas do requeijão obtido na Formulação 2, na qual foi utilizado o sal fundente JOHA S9 e o CPS 34\% como substituto parcial da gordura 


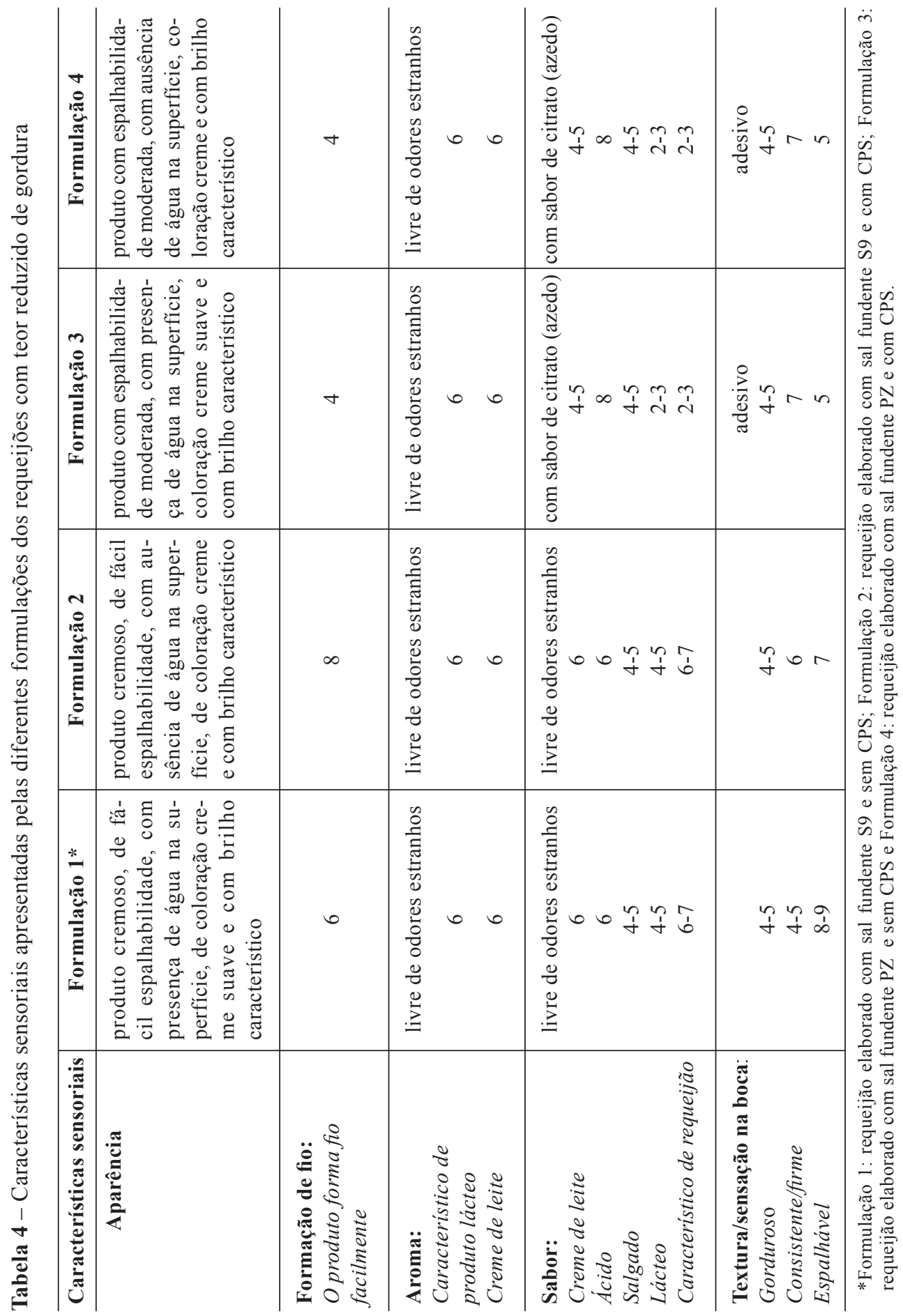


Com relação à Formulação 1 (sem adição de CPS 34\%), observou-se que as características sensoriais apresentadas pela mesma foram bem próximas às obtidas para a Formulação 2, com exceção da firmeza, que foi um pouco menor. Porém, nesta formulação ocorreu uma pequena separação de água na superfície, o que gerou rejeição por parte dos julgadores.

Pinto et al. (2007) também observaram a melhora da firmeza e espalhabilidade de queijos processados espalháveis contendo CPS com $38 \%$ proteína.

\section{CONCLUSÕES}

Adaptações e modificações na tecnologia tradicional de fabricação de requeijão cremoso e a utilização de um substituto de gordura foram essenciais para obtenção de um produto com teor reduzido de gordura que apresentasse características sensoriais adequadas.

Nesta pesquisa, o requeijão cremoso com teor reduzido de gordura que apresentou as melhores características foi aquele produzido com massa obtida por acidificação direta a quente, com temperatura de precipitação da massa na faixa dos $68-70{ }^{\circ} \mathrm{C}$, no qual foram empregados $1,3 \%$ de sal fundente JOHA S9 na fusão da massa e $2 \%$ de concentrado protéico de soro (CPS 34\%) como substituto parcial de gordura, ambos calculados em relação à massa básica. Além disso, observou-se que o momento mais adequado para a adição do CPS ao produto foi quando o mesmo se encontrava a uma temperatura de aproximadamente $70{ }^{\circ} \mathrm{C}$.

\section{REFERÊNCIAS}

AGÊNCIA NACIONAL DE VIGILÂNCIA SANITÁRIA (ANVISA). Resolução RDC $n^{\circ} 54$, de 12 de novembro de 2012. Dispõe sobre o Regulamento Técnico sobre Informação
Nutricional Complementar. Diário Oficial da República Federativa do Brasil, Brasília, 13 nov. 2012. Seção 1, p. 219.

ANTUNES, A. J. Funcionalidade de proteínas do soro de leite bovino. Barueri: Manole, 2003. 135p.

ASSOCIATION OF OFFICIAL ANALYTICAL CHEMISTS (AOAC). Official Methods of Analysis. 16 ed. Washington: AOAC, DC, 1997. v. 2, 850 p.

ATHERTON, H. V.; NEWLANDER, J. A. Chemistry and testing of dairy products. $4^{\text {th }}$ ed. Westport: AVI Publishing, 1981. 396 p.

BRASIL. Ministério da Agricultura e do Abastecimento. Secretaria de Defesa Agropecuária. Departamento Nacional de Inspeção de Produtos de Origem Animal. Portaria $\mathrm{n}^{\circ} 356$, de 4 de setembro de 1997. Aprova o Regulamento Técnico para Fixação de Identidade e Qualidade de Queijo Processado ou Fundido, Processado Pasteurizado e Processado ou Fundido U.H.T (UAT). Diário Oficial da República Federativa do Brasil, Brasília, 08 set.1997. Seção 1, p. 19687.

BRASIL. Ministério da Saúde. Secretaria de Atenção à Saúde. Coordenação-Geral da Política de Alimentação e Nutrição. Guia alimentar para a população brasileira: promovendo a alimentação saudável / Ministério da Saúde. Secretaria de Atenção à Saúde. Coordenação-Geral da Política de Alimentação e Nutrição. Brasília: Ministério da Saúde, 2005. 236p. (Série A. Normas e Manuais Técnicos). Disponível em: <http:// dtr2001.saude.gov.br/editora/produtos/livros/ pdf/05_1109_M.pdf>. Acesso em: 10 jul. 2013.

BRASIL. Ministério da Saúde. Secretaria de Vigilância em Saúde. Departamento de 
Análise de Situação de Saúde. Plano de Ações Estratégicas para o Enfrentamento das Doenças Crônicas não Transmissíveis (DNCT) no Brasil 2011-2022. Série B. Textos Básicos de Saúde. Brasília: Ministério da Saúde, 2011. 160p.

BRASIL. Ministério da Saúde. Secretaria de Atenção à Saúde. Departamento de Atenção Básica. Política Nacional de Alimentação e Nutrição / Ministério da Saúde. Secretaria de Atenção à Saúde. Departamento de Atenção Básica. Série B. Textos Básicos de Saúde Brasília: Ministério da Saúde, 2012. 84p.

BRICKLEY, C. A. et al. Influence of Emulsifying Salts on the Textural Properties of Nonfat Process Cheese Made from Direct Acid Cheese Bases. Journal of Dairy Science, v. 91, n. 1, p. 39-48, 2008.

DRAKE, M. A.; SWANSON, B. G. Reduced and low fat cheese technology: A review. Trends in Food Science \& Technology, v. 6, n. 11, p. 366-369, 1995.

FERNANDES, A. G.; MARTINS, J. F. P. Fabricação de requeijão cremoso a partir de massa obtido por precipitação ácida a quente de leite de búfala e de vaca. Revista do Instituto de Laticínios Cândido Tostes, v. 35, n. 212, p. 7-13, 1980.

FERNANDES, A. G. Processamento: tipos e cálculos. In: MARTINS, J. F. P.; FERNANDES, A. G. (Ed.). Processamento de requeijão cremoso e outros queijos fundidos. Campinas: ITAL, 1981. cap. 7, p. 1-14.

FOX et al. Microbiology of cheese ripening. In: FOX et al. Fundamentals of Cheese Science. Gaithersburg: Aspen Publishers, 2000. cap. 10, p. 206-235.

Instituto ADOLfo LUTZ. Métodos físico-químicos para análise de alimentos.
4 ed. São Paulo: Instituto Adolfo Lutz, 2005. $1020 \mathrm{p}$.

INTERNATIONAL DAIRY FEDERATION (IDF). Determination of the total solids content of cheese and processed cheese. Belgium: FIL/IDF, 1982. 2p. (FIL/IDF, 4A).

INTERNATIONAL ORGANIZATION FOR STANDARDIZATION (ISO). ISO 6658:2005: Sensory analysis - Methodology - General guidance. ISO, 2005. 20 p.

KAPOOR, R.; METZGER, L. E. Process Cheese: Scientific and Technological Aspects - A Review. Comprehensive Reviews in Food Science and Food Safety, v. 7, p. 194-214, 2008.

LEE, S. K.; ANEMA, S. G. The effect of the $\mathrm{pH}$ at cooking on the properties of processed cheese spreads containing whey proteins. Food Chemistry, v. 115, n. 4, p. 1373-1380, 2009.

LUCCA, P. A.; TEPPER, B. J. Fat replacers and the functionality of fat in foods. Trends in Food Science and Technology, v. 5, n. 1, p. 12-19, 1994

MAURER-ROTHMANN, A.; SCHEURER G. Stabilization of milk protein systems. A Joha Guide. BK Giulini Gmbh, Ludwigshafen, Germany, 2005. 50p.

MISTRY, V. V. Low fat fermented milk products. In: CONGRESSO BRASILEIRO DE CIÊNCIA E TECNOLOGIA DE ALIMENTOS, 13., 2002, Porto Alegre. Anais... Porto Alegre, 2002.1 CD- ROM

NACHAY, K. Combating Obesity. Food Technology, v. 62, n. 2, p. 24-33, 2008.

NEVES, B. S.; DUCRUET, P. Emprego da ultrafiltração na fabricação de requeijão 
cremoso. Revista do Instituto de Laticínios Cândido Tostes, v. 43, n. 257, p. 3-8, 1988.

O'MAHONY, J. A.; MCSWEENEY, P. L. H.; LUCEY, J. A. A model system for studying the effects of colloidal calcium phosphate concentration on the rheological properties of Cheddar cheese. Journal of Dairy Science, v. 89, n. 3, p. 892-904, 2006.

ORGANIZAÇÃO MUNDIAL DE SAÚDE (OMS). Cardiovascular diseases (CVDs). [2009]. Disponível em:<htpp://www.who.int/ mediacentre/factsheets/fs317/en/index.html>. Acesso em: 5 fev. 2010.

PATART, J. P. Les Fromages Fondus. In: Le fromage. Paris: Tecnique et Documentation (Lavoisier), 1984. p. 385-399.

PINTO, S. et al. Utilization of whey protein concentrate in processed cheese spread. Natural Product Radiance, v. 6, n. 5, p. 398-401, 2007.

ROLLER, S.; JONES, S. A. Handbook of fat replacers. Florida: CRC Press, 1996. $336 \mathrm{p}$.

SAMPAIO, L. G. A.; BRANDÃO, S.C.C. Desenvolvimento de requeijão cremoso light utilizando Dairy-Lo. Revista do Instituto de Laticínios Cândido Tostes, v. 50, p. 211213, 1995. Anais do XII Congresso Nacional de Laticínios.
SILVA, A. T. et al. Comparação de métodos para determinação do teor de gordura em requeijão cremoso tradicional e com teor de gordura reduzido. Revista do Instituto de Laticínios Cândido Tostes, v. 57, n. 327, p. 262-265, 2002.

SOLER, M. Redução e Substituição. In: VIALTA, A.; REGO, R.A (Ed.). Brasil Ingredients Trends 2020. Campinas: ITAL, 2014. cap. 13 , p. 295-309.

VAN DENDER, A. G. F.; GALLINA, D. A.; ZACARCHENCO, P. B. Características dos sais fundentes e seu papel na obtenção de queijos processados. In: VAN DENDER, A. G. F. (Ed.). Requeijão cremoso e outros queijos fundidos: Tecnologia de fabricação, controle de processo e aspectos de mercado. São Paulo: Setembro, 2014. cap. 2, p. 29, 56.

U.S. DAIRY EXPORT COUNCIL (USDEC). Manual de referência para produtos de soro e lactose dos EUA. São Paulo: USDEC, 2004. 226p.

WEISEROVÁ, E. et al. The effect of combinations of sodium phosphates in binary mixtures on selected texture parameters of processed cheese spreads. International Dairy Journal, v. 21, n. 12, p. 979-986, 2011.

YACKEL, W. C.; COX, C. Application of starch-based fat replacers. Food Technology, v. 46, n. 6, p. 146-148, 1992. 